\title{
Expression of GA733-Fc Fusion Protein as a Vaccine Candidate for Colorectal Cancer in Transgenic Plants
}

\author{
Zhe Lu, ${ }^{1}$ Kyung-Jin Lee, ${ }^{2,3}$ Yingxue Shao, ${ }^{1}$ Jeong-Hwan Lee, ${ }^{1}$ Yangkang So, ${ }^{1}$ \\ Young-Kug Choo, ${ }^{2}$ Doo-Byoung Oh, ${ }^{3}$ Kyung-A Hwang, ${ }^{4}$ Seung Han Oh, ${ }^{5}$ \\ Yeon Soo Han, ${ }^{5}$ and Kisung Ko ${ }^{1}$ \\ ${ }^{1}$ Department of Medicine, Medical Research Institute, College of Medicine, Chung-Ang University, Seoul 156-756, Republic of Korea \\ ${ }^{2}$ Division of Biological Science, College of Natural Sciences, Wonkwang University, Iksan, Jeonbuk 570-749, Republic of Korea \\ ${ }^{3}$ Korea Research Institute of Bioscience \& Biotechnology, Daejeon 305-806, Republic of Korea \\ ${ }^{4}$ Department of Agrofood Resources, National Academy of Agricultural Science, RDA, Suwon, Gyeonggi-do 441-707, Republic of Korea \\ ${ }^{5}$ Department of Applied Biology, College of Agriculture \& Life Science, Chonnam National University, Gwangju 500-757, Republic of \\ Korea
}

Correspondence should be addressed to Kisung Ko, ksko@cau.ac.kr

Received 5 December 2011; Revised 19 February 2012; Accepted 10 March 2012

Academic Editor: Nathan A. Ellis

Copyright () 2012 Zhe Lu et al. This is an open access article distributed under the Creative Commons Attribution License, which permits unrestricted use, distribution, and reproduction in any medium, provided the original work is properly cited.

\begin{abstract}
The tumor-associated antigen GA733 is a cell-surface glycoprotein highly expressed in colorectal carcinomas. In this study, 3 recombinant genes were constructed as follows: GA733 tagged to the ER retention sequence KDEL (GA733K), GA733 fused to the immunoglobulin Fc fragment (GA733-Fc), and GA733-Fc fused to the ER retention sequence (GA733-FcK). Agrobacteriummediated transformation was used to generate transgenic plants expressing recombinant genes. The presence of transgenes was confirmed by genomic PCR. Western blot, confocal immunofluorescence, and sandwich ELISA showed the expression of recombinant proteins. The stability, flexibility, and bioactivity of recombinant proteins were analyzed and demonstrated through N-glycosylation analysis, animal trials, and sera ELISA. Our results suggest that the KDEL retained proteins in ER with oligomannose glycan structure and enhanced protein accumulation level. The sera of mice immunized with GA733-FcK purified from plants contained immunoglobulins which were at least as efficient as the mammalian-derived GA733-Fc at recognizing human colorectal cancer cell lines. Thus, a plant system can be used to express the KDEL fusion protein with oligomannose glycosylation, and this protein induces an immune response which is comparable to non-KDEL-tagged, mammalian-derived proteins.
\end{abstract}

\section{Introduction}

Immunization with tumor-associated antigen (TAA) is a potential approach for cancer treatment and prevention [1]. Cancer vaccines have not been administered to prevent a tumor from occurring in healthy individuals. Instead, they have been used to alleviate the suffering of patients who are already combating cancer [2]. GA733 is an epithelial cell adhesion molecule (EpCAM) that is abundant in colorectal cancer cells [3]. In addition, GA733 is known to mediate $\mathrm{Ca}^{2+}$-independent homotypic cell-cell adhesion [4]. It contains an extracellular domain with 2 epidermal growth factor-(EGF-) like repeats, followed by a cysteine-poor region, a transmembrane domain, and a short (26 amino acid) cyto- plasmic tail [5]. The extracellular domain (ECD) of GA733 is often used as a target for cancer vaccination [6]. Such recombinant vaccines developed over the last several decades have been expressed using many available heterologous expression systems [7]. Plants are a promising expression system that can efficiently produce recombinant proteins in large quantities without pathogenic animal contaminants [8].

Recently, the tumor-associated colorectal cancer antigen EpCAM (GA733) was expressed in plants, and the recombinant plant-derived antigen induced a humoral immune response in BALB/c mice [9]. However, plants are not an ideal expression system for producing therapeutic proteins because of the differences in the $\mathrm{N}$-glycosylation processes between plants and humans and the low expression level 
[10]. Plant-derived specific $N$-glycans contain antigenic and/or allergenic $\beta(1,2)$-xylose and $\alpha(1,3)$-fucose, which are absent in mammalian glycans [11]. The plant-specific glycans lack sialic acid, which may cause instability and a lower half-life [12]. To avoid the plant-derived specific $\mathrm{N}$-glycan structure, we generated an oligomannose glycan structure by retaining the recombinant protein (GA733 and $\mathrm{GA733}-\mathrm{Fc}$ ) in the endoplasmic reticulum (ER). Fusion of GA733 or GA733-Fc to KDEL (the ER retention motif, Lys-Asp-Glu-Leu) [13] helps retain the protein inside the ER and at the same time enhances GA733 and GA733-Fc assembly in plant cells. The antigen-antibody complex may potentially have properties similar to the parental IgG, such as enhanced efficacy of vaccination by targeting the vaccine to antigen-presenting cells (APCs), facilitated purification by the protein-A method, and increased half-life [2, 14-16]. Furthermore, an antigen-antibody chimera was reported to provide higher expression levels, better yields, and increased stability in plant expression systems [2,17].

In the present study, 3 different recombinant human colorectal cancer antigen GA733 genes were expressed in a tobacco (Nicotiana tabacum) plant expression system: GA733 fused to the immunoglobulin Fc fragment (GA733Fc), GA733-Fc with KDEL (GA733-FcK), and GA733 with KDEL (GA733K). The stability and functionality of these colorectal cancer vaccine candidates were confirmed by western blot analysis and ELISA, respectively. In order to understand the fusion of Fc to GA733 and its functionality, the immunogenicity of recombinant GA733-Fc with oligomannose glycosylation was investigated in mice.

\section{Materials and Methods}

2.1. Construction of the Plant Expression Vector. The synthetic DNA sequence encoding GA733 (Gln38-Lys279, GenBank accession no. AY189981) was modified by N-terminal extension with a 30-aa plant ER signal peptide (MATQRRANPSSLHLITVFSLLAAVVSAEVD) from Nicotiana plumbaginifolia and C-terminal extension with an ER retention signal (KDEL). The recombinant chimeric protein GA733-Fc was generated by fusing GA733 to the Fc fragment of human IgG1 (Val97-Gly328, GenBank accession no. AY172957). The Lys279 (C-terminus of GA733) was followed by the Val97 (N-terminus of Fc fragment of human IgG1). The GA733-Fc-encoding sequences were placed under the control of the enhanced cauliflower mosaic virus (CaMV) $35 \mathrm{~S}$ promoter and tobacco etch viral $5^{\prime}$-leader sequence (TEV). The GA733, GA733-Fc, and GA733-FcK expression cassettes were subcloned into the HindIII sites of the binary plant transformation vector pBIN-Plus to yield pBI GA733K, pBI GA733-FcK, and PBI GA733-Fc, respectively (Figure 1(a)).

2.2. Plant Transformation. Recombinant vectors were introduced into the Agrobacterium tumefaciens strain LBA4404 by electroporation. Transgenic tobacco plants were generated by Agrobacterium-mediated transformation [11]. Transgenic tobacco lines were selected on Murashige and
Skoog medium (Dachfu, Haarlem, Netherland) containing $100 \mathrm{mg} / \mathrm{L}$ kanamycin. Transgenic plantlets were then transferred to soil in a growth chamber at a constant temperature of $23^{\circ} \mathrm{C}$ and $70 \%$ humidity and were maintained under a 14: $10 \mathrm{~h}$ light-dark cycle. Transgenic and nontransgenic $N$. tabacum plants were grown in a greenhouse under controlled conditions.

2.3. PCR Amplification of Genomic DNA. Genomic DNA was isolated from the fresh leaf tissue of transgenic and non-transgenic plants using a DNA extraction kit (iNtRON Biotechnology, Seoul, Republic of Korea) according to the manufacturer's recommendations. PCR amplification of genomic DNA was performed in order to confirm the presence of the recombinant genes using the following primer pairs: for GA733K, forward primer $5^{\prime}$-GCG TCG ACA CGG CGA CTT TGC CGC TCA GGA A-3', reverse primer 5'-GCT CTA CAT CAG AGT TCA TCT TTT TTT AGA CCC TCG ATT GAG-3'; for GA733-FcK, forward primer $5^{\prime}$-GCG TCG ACA CGG CGA CTT TTG CCG CAG CTC AGG AA-3', reverse primer 5'-GCT CTA GAT CAG AGT TCA TCT TTA CCC GGG GAC AGG G-3'; for GA733Fc, forward primer $5^{\prime}$-GCG TCG ACA CGG CGA CTT TGC CGC AGC TCA GGA A-3', reverse primer 5'-GCT CTA GAT CAA CCC GGG GAC AGG GAG AG-3'. PCR was performed with 38 cycles of $94^{\circ} \mathrm{C}$ for $60 \mathrm{~s}, 55^{\circ} \mathrm{C}$ for $60 \mathrm{~s}$, and $72^{\circ} \mathrm{C}$ for $60 \mathrm{~s}$. Non-transgenic plants were used as negative control, while a T-easy vector (Promega, Madison, WI, USA) containing the GA733-FcK gene was used as a positive control. The expected size of the DNA products for GA733K, GA733-FcK, and GA733-Fc was 768, 1483, and $1471 \mathrm{bp}$, respectively.

2.4. RNA Isolation and Semiquantitative RT-PCR. The transcription levels of GA733K, GA733-FcK, and GA733-Fc mRNA were quantified by performing semi-quantitative RTPCR. Total RNA was extracted from transgenic and nontransgenic plants using the RNeasy plant mini kit (Qiagen, Valencia, CA, USA), according to the manufacturer's protocol. To remove the genomic DNA, $600 \mathrm{ng}$ of total RNA was treated using a TURBO DNA-free kit (Ambion, Austin, TX, USA) in a reaction volume of $20 \mu \mathrm{L}$. The RNA samples were stored at $-80^{\circ} \mathrm{C}$ until use. Each RNA sample was used as a template for RT reactions performed using AccuPower RT/PCR PreMix (Bioneer, Daejeon, Republic of Korea). RTPCR was performed using the following master mix: $4 \mu \mathrm{L}$ $10 \times$ RT-PCR buffer, $2 \mu \mathrm{L}$ for each primer $(10 \mathrm{pmol} / \mu \mathrm{L}), 2 \mu \mathrm{L}$ $10 \mathrm{mM}$ dNTPs, and $1 \mu \mathrm{L}$ of HotStart Taq DNA polymerase (Bioneer); the volume of the mix was adjusted to $22 \mu \mathrm{L}$ with sterilized water, and $3 \mu \mathrm{L}$ of RNA was added as a template. The following primers were used in the RT-PCR reaction: for GA733K, forward primer 5' -GCA GCT CAG GAA GAA TCT-3', reverse primer 5' -CTC AGA GCA GGT TAT TTC A-3'; for GA733-FcK or GA733-Fc, forward primer 5'-ATC TGG ATC CTG GTC AAA-3', reverse primer $5^{\prime}$-CTC AGA GCA GGT TAT TTC A-3'; for actin (GenBank accession No. X69885), forward primer $5^{\prime}$-AAT CCA CGA GAC TAC ATA CAA- $3^{\prime}$, reverse primer $5^{\prime}$-AGA GCC TCC AAT CCA GAC 

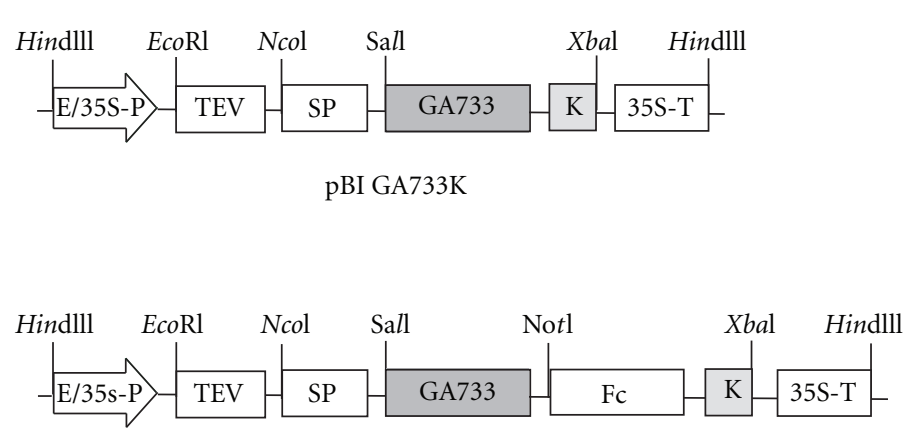

pBI GA733-FcK

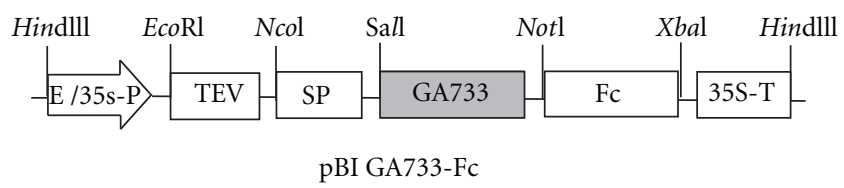

(a)
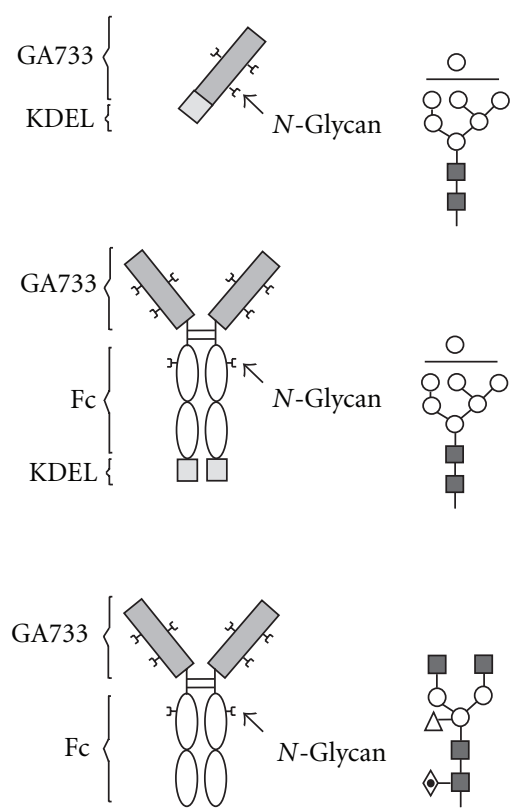

(b)

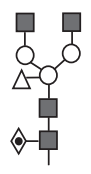

(c)

FIGURE 1: Schematic diagram of plant expression vectors and recombinant proteins. (a) Gene expression cassettes of GA733K, GA733-FcK, and GA733-Fc. E/35S-P, the Cauliflower mosaic virus 35S promoter with duplicated enhancer region; TEV, untranslated leader sequence of tobacco etch virus; SP, endoplasmic reticulum signal peptide; KDEL, ER retention signal; 35S-T, terminator of Cauliflower mosaic virus $35 \mathrm{~S}$ gene. (b) Structure of recombinant proteins. (c) N-glycan structures of recombinant proteins GA733K, GA733-FcK, and GA733-Fc. The symbols of the glycan structures are as follows: $N$-acetylglucosamine, black square; mannose, white circle; fucose, diamond with a dot inside; xylose, white triangle.

A-3'. The RNA was subjected to RT-PCR with the following specifications: reverse transcription at $50^{\circ} \mathrm{C}$ for $30 \mathrm{~min}$; an initial PCR activation step at $95^{\circ} \mathrm{C}$ for $15 \mathrm{~min} ; 38$ cycles of $1 \mathrm{~min}$ at $94^{\circ} \mathrm{C}, 1 \mathrm{~min}$ at $55^{\circ} \mathrm{C}$, and $1 \mathrm{~min}$ at $72^{\circ} \mathrm{C}$; a final extension at $72^{\circ} \mathrm{C}$ for $10 \mathrm{~min}$. The predicted sizes of the RTPCR products for GA733K, GA733-FcK, and GA733-Fc are 348,534 , and $534 \mathrm{bp}$, respectively. The actin gene (214 bp) is used as an endogenous control. The RT-PCR products were analyzed on $1.0 \%$ agarose gel.

2.5. Immunoblot Analysis. In order to evaluate the stability of GA733K, GA733-FcK, and GA733-Fc, a leaf tissue (100 mg) was homogenized in $1 \times$ PBS in the presence or absence of complete protease inhibitor cocktail (Roche Diagnostics, Mannheim, Germany). The proteins in the homogenates were resolved by $12.5 \%$ SDS-PAGE and transferred to a nitrocellulose membrane (Millipore, Billerica, MA, USA). Membranes were incubated with blocking buffer (3\% skim milk (Fluka, Buchs, Switzerland) in PBS plus $0.5 \%(\mathrm{v} / \mathrm{v})$ Tween 20). The blots were incubated for $1 \mathrm{~h} 30 \mathrm{~min}$ at RT with either mouse anti-EpCAM antibody (R\&D systems, Minneapolis, MN, USA) diluted in blocking buffer at 1:500 or mouse anti-human Fcy conjugated to horseradish peroxidase (Jackson ImmunoResearch, West Grove, PA, USA) diluted in blocking buffer at $1: 3,000$ and then incubated for $1 \mathrm{~h}$ and $30 \mathrm{~min}$ at RT with secondary antibody goat antimouse IgG (Animal Genetics, Daejeon, Republic of Korea) diluted in blocking buffer at $1: 3,000$.
Anti-Fc $y$ recognizes the Fc portion of GA733-Fc, while antihuman GA733 antibody detects GA733. Protein bands were visualized by exposing the membrane to an X-ray film (Fuji, Tokyo, Japan) using a chemiluminescence substrate (Pierce). Non-transgenic plants and the recombinant human EpCAM/TROP-1 Fc chimera (R\&D systems), of which the human EpCAM/TROP-1 is fused with the Fc fragment of human IgG1, were used as negative and positive controls, respectively.

2.6. Confocal Microscopy Analysis. To reconfirm the expression of recombinant proteins, confocal microscopy analysis was carried out. The leaf samples were collected from the 3 transgenic plants (GA733K, GA733-FcK, and GA733-Fc) and a non-transgenic plant and were then fixed in formalinacetic acid-alcohol solution for $24 \mathrm{~h}$. The fixed leaves were dehydrated in ethanol, cleared in xylene, and embedded in paraffin blocks. The paraffin blocks were sectioned into 7$\mu \mathrm{m}$ slices and attached to gelatin-coated slides. The sectioned tissues were rehydrated with xylene and ethanol. The tissue slides were incubated with $1 \%$ bovine serum albumin in $0.01 \mathrm{M}$ PBS ( $\mathrm{pH}$ 7.2) to block nonspecific binding of the primary antibody. The primary antibodies, mouse antiGA733 IgG, and goat anti-human IgG Fc antibody (Animal Genetics), were diluted 1:500 in PBS and applied to samples for $3 \mathrm{~h}$ at RT. The tissue slides were then incubated for another $3 \mathrm{~h}$ at RT with the secondary antibodies, Alexa488 conjugated anti-mouse IgG (Invitrogen, CA, USA) and 


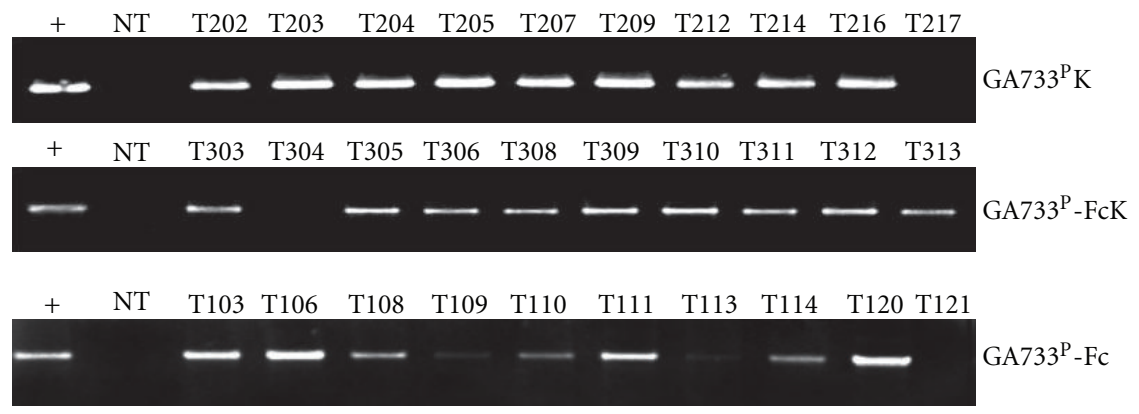

FIGURE 2: PCR analysis of genomic DNA from transgenic plants. Genomic DNA of GA733K (780 bp), GA733-FcK (1473 bp), and GA733-Fc (1461 bp) transgenic plants. +: positive control, T-easy vector with gene of interest; NT: negative control, genomic DNA from non-transgenic tobacco plants.

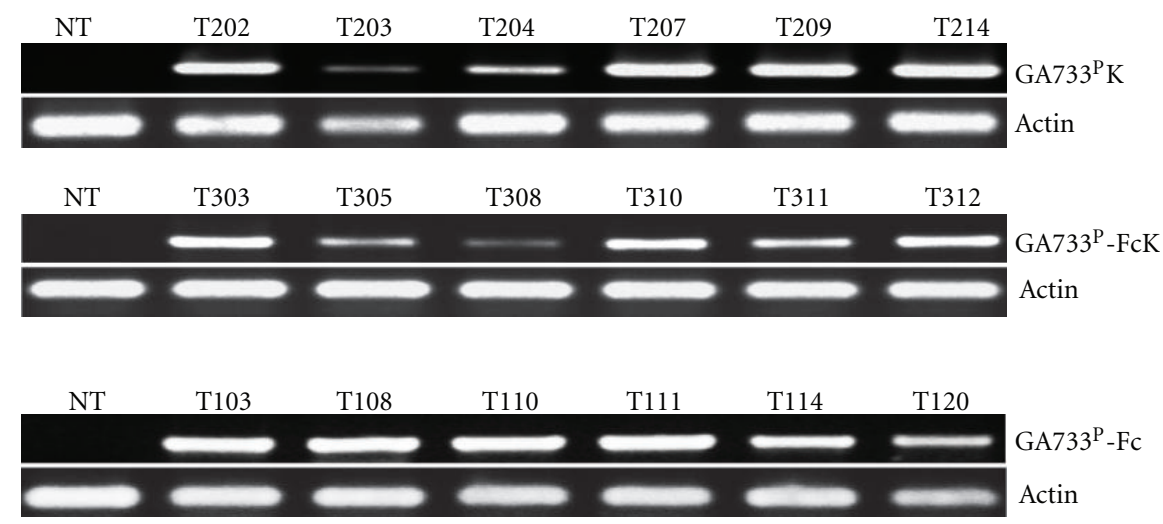

FIgURE 3: RT-PCR analysis of recombinant gene expression in transgenic plant. RT-PCR analysis of GA733K (348 bp), GA733-FcK (534 bp), and GA733-Fc (534 bp). NT: negative control, non-transgenic plant. The actin gene (214 bp) was used as an endogenous control.

Alexa-546 conjugated anti-goat IgG (Invitrogen), diluted $1: 300$ in PBS. In order to stain the nucleus, the slides were incubated with TO-PRO-3 iodide (Invitrogen). Anti-human IgG and TO-PRO-3 fluorescence was observed using a confocal laser scanning microscope (Olympus, Tokyo, Japan) at $488 \mathrm{~nm}$ and $633 \mathrm{~nm}$, respectively.

2.7. Sandwich ELISA. The expression and assembly of vaccine candidates in plants were further analyzed by sandwich ELISA. Briefly, 96-well MaxiSorp surface plates (Nunc, Rochester, NY, USA) were coated with $1 \mu \mathrm{g} / \mathrm{mL}$ mouse antihuman GA733 antibody in $50 \mathrm{mM}$ sodium carbonate $(\mathrm{pH}$ 9.6). The leaf tissues ( $100 \mathrm{mg}$ ) were homogenized in $200 \mu \mathrm{L}$ of extraction buffer containing $10 \mathrm{mM}$ sodium sulfate, $2 \%$ polyvinylpyrrolidone (molecular weight, 40,000 kDa), $3 \mathrm{mM}$ sodium azide, and $0.5 \%$ Tween 20 . Leaf extract samples were diluted 2-fold in extraction buffer, and then serial 3-fold dilutions were made in PBS. Recombinant human EpCAM/TROP-1 Fc chimera (R\&D systems, $5 \mu \mathrm{g} / \mathrm{mL}$ ) was used as a positive control, and a rabies antibody (Bethyl, Montgomery, TX, USA) was used as a negative control. The plate was incubated with secondary antibody goat antihuman Fcy conjugated to horseradish peroxidase (Jackson ImmunoResearch $)(1: 3,000)$ diluted in PBS for $2 \mathrm{~h}$ at RT and was detected using soluble TMB (3.3', 5.5'-tetramethylbenzidine) substrate (KPL, Gaithersburg, MD, USA). The antibody titers in 3 wells per tested sample were estimated by determining the optical density at $450 \mathrm{~nm}$ using an ELISA reader Sunrise (TECAN, Männedorf, Switzerland).

2.8. Isolation and Purification of Plant-Derived Recombinant Chimeric Protein. Isolation and purification procedures of the recombinant proteins were followed as described in a previous study [18]. Plant leaves were homogenized in an HR2094 Aluminium Blender (PHILIPS, Seoul, Republic of Korea) in chilled extraction buffer $(37.5 \mathrm{mM}$ Tris- $\mathrm{HCl}$, $50 \mathrm{mM} \mathrm{NaCl}, 15 \mathrm{mM}$ EDTA, $75 \mathrm{mM}$ sodium citrate, and $0.2 \%$ sodium thiosulfate). After centrifugation for $30 \mathrm{~min}$ at $15,000 \times \mathrm{g}$, the supernatants were further clarified through a Miracloth (Calbiochem, La Jolla, CA, USA), and solid ammonium sulfate was added $16 \%$ saturation. After $2 \mathrm{~h}$ incubation at $4^{\circ} \mathrm{C}$, the solution was centrifuged at $15,000 \times \mathrm{g}$ for $30 \mathrm{~min}$ at $4^{\circ} \mathrm{C}$, the precipitate was discarded, and ammonium sulfate was added to the supernatant to $40 \%$ saturation. After incubation at $4^{\circ} \mathrm{C}$ overnight, the solution was centrifuged at $15,000 \times \mathrm{g}$ for $30 \mathrm{~min}$ at $4^{\circ} \mathrm{C}$, and the pellet was resuspended in extraction buffer at one-fifth of the original volume. Soluble protein extract was applied to a protein A column (GE Healthcare, Piscataway, NJ, USA). Eluates of plant-derived recombinant GA733-Fc protein were dialyzed against $1 \times$ PBS buffer and brought to a final concentration of $1 \mathrm{mg} / \mathrm{mL}$ using an Amicon Ultra spincolumn with a $10 \mathrm{kDa}$ cutoff (Millipore). Aliquots were frozen in liquid nitrogen and stored at $-80^{\circ} \mathrm{C}$. For analysis, extracts 


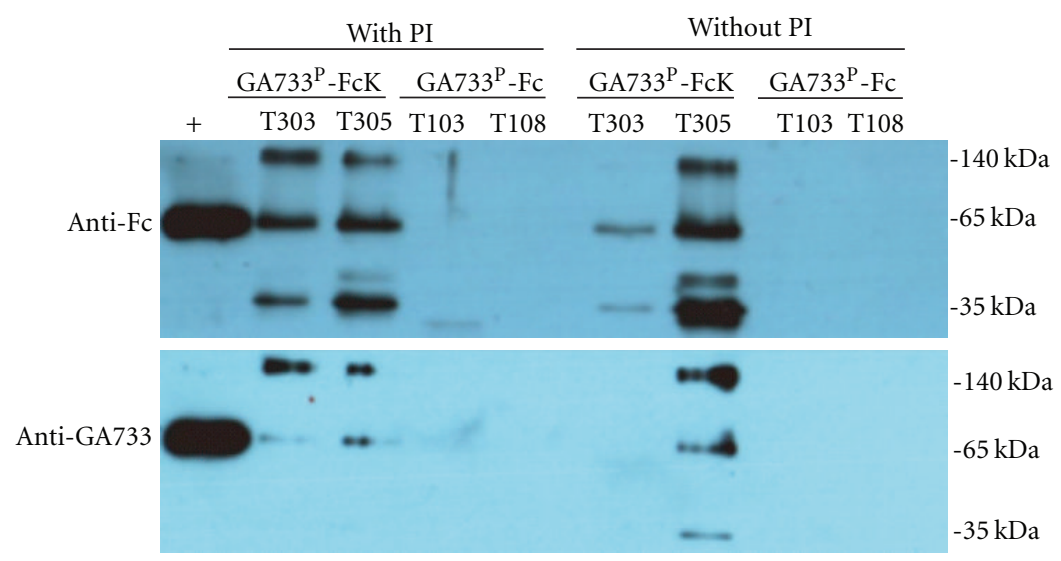

FIGURE 4: Western blot of GA733-FcK and GA733-Fc expression. Leaf samples from GA733-FcK and GA733-Fc transgenic plants were ground with extraction buffer containing protease inhibitor (With PI) or not (Without PI) to confirm the stability of proteins. Soluble proteins were detected by mouse anti-human Fc $\gamma$ antibody and mouse anti-human GA733 antibody. +: positive control, human EpCAM/TROP-1 (GA733) Fc chimera.
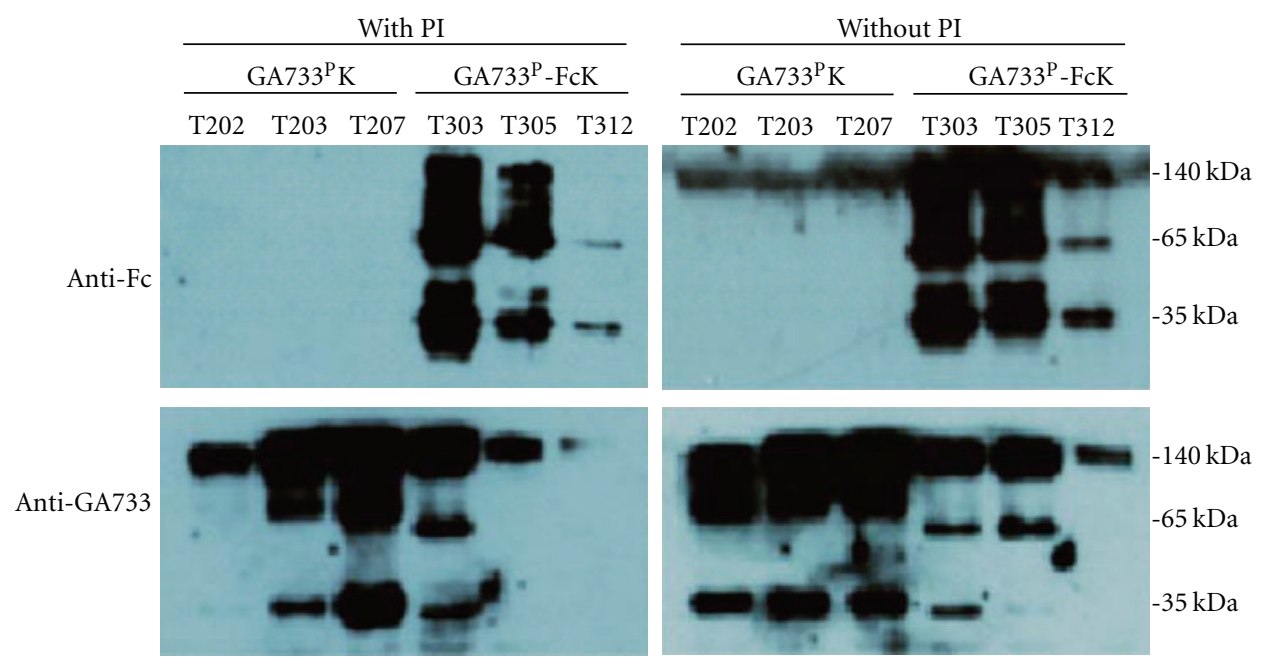

FIGURE 5: Western blot of GA733K and GA733-FcK expression. Leaf samples from GA733K and GA733-FcK transgenic plants were ground with extraction buffer containing protease inhibitor (With PI) or not (Without PI) to confirm the stability of proteins. Soluble proteins were detected by mouse anti-human Fc $\gamma$ antibody and mouse anti-human GA733 antibody.

were resolved by SDS-polyacrylamide gel electrophoresis (PAGE) and either stained or transferred to a nitrocellulose membrane (Millipore), blocked with 3\% nonfat milk and murine anti-GA733 IgG (Calbiochem, San Diego, CA, USA), and followed by secondary antimurine mAb conjugated to horseradish peroxidase (Sigma, St. Louis, MO, USA) diluted $1: 10,000$ to detect GA733. For Fc detection, the secondary antimurine IgG conjugated to horseradish peroxidase was used. Non-transgenic plants and the recombinant human EpCAM/TROP-1 Fc chimera (R\&D systems) were used as negative and positive controls, respectively. Reactive protein bands were visualized using the chemiluminescent peroxidase substrate (Pierce).

2.9. N-Glycan Profile Analysis. Samples were first digested into glycopeptides using pepsin, as previously described [19]. From the resulting glycopeptide mixtures, $\mathrm{N}$-glycans were released using peptide $N$-glycosidase (PNGase) A (Roche,
Basel, Switzerland). The released $N$-glycans were purified using graphitized carbon resin from Carbograph (Alltech, Lexington, MA, USA). Purified glycans were dried and then redissolved in a mixture of $90 \mu \mathrm{L}$ dimethyl sulfoxide (DMSO), $2.7 \mu \mathrm{L}$ water, and $35 \mu \mathrm{L}$ iodomethane for solid phase permethylation using a spin-column method [20]. After the process previously described, the chloroform layer containing permethylated glycans was dried and resuspended in $4 \mu \mathrm{L}$ of a $50 \%$ methanol solution. Then, it was mixed in equal volume with the matrix 2,5-dihydroxybenzoic acid prepared in $1 \mathrm{mM}$ sodium acetate solution. The resulting mixtures were applied onto an MALDI MSP 96 polished steel Chip (Bruker Daltonik GmbH, Bremen, Germany) and dried. Matrix-assisted laser desorption/ionization-time of flight (MALDI-TOF) mass spectrometry was performed in the reflector positive ion mode using a Microflex (Bruker Daltonik). All mass spectra were acquired at a $20 \mathrm{kV}$ accelerating voltage using the method recommended by the manufacturer. 


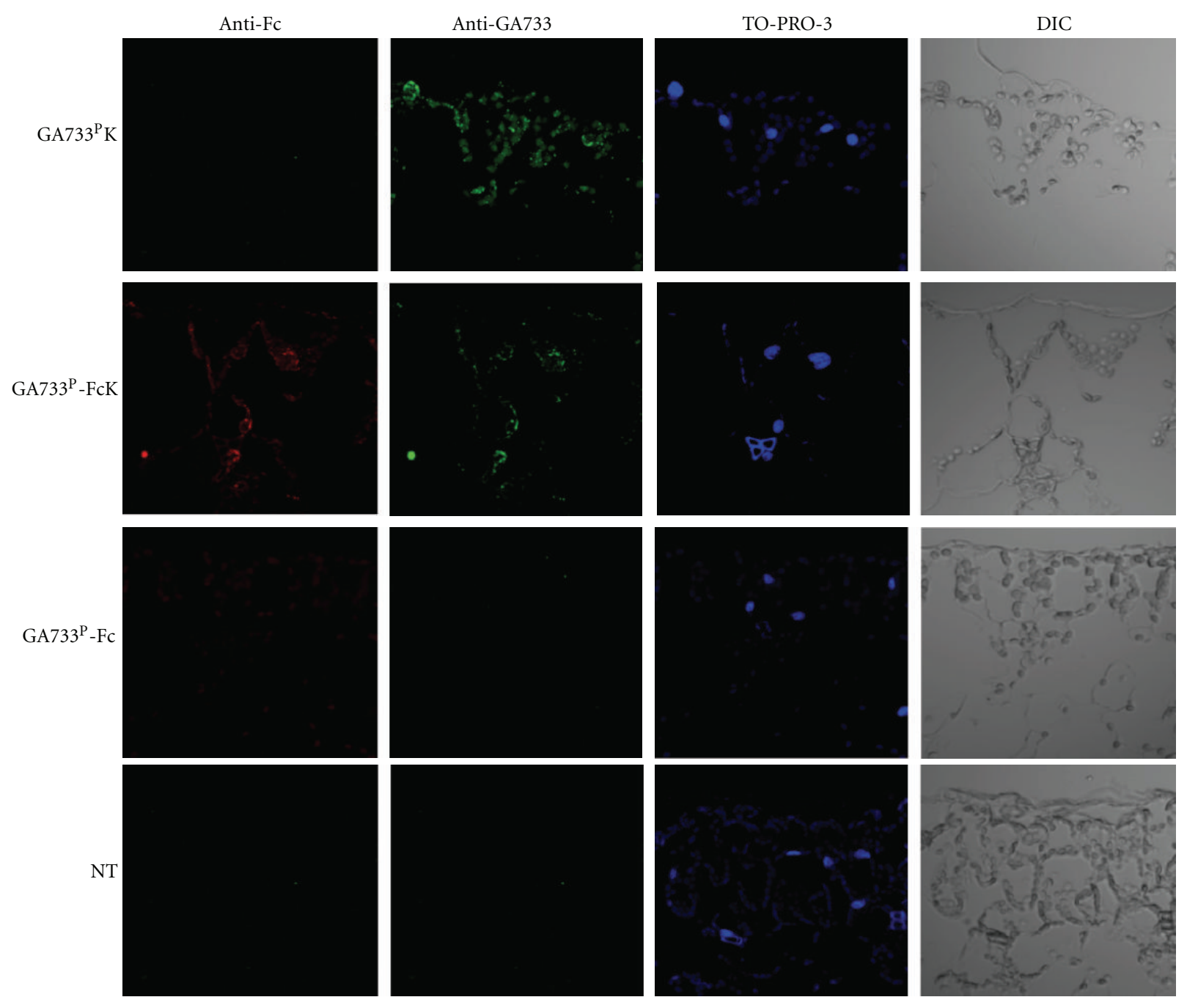

FIGURE 6: Confocal immunofluorescence analysis of GA733K, GA733-FcK, and GA733-Fc expressed in transgenic plant cells. The Fc fragment was detected by Alexa-546 conjugated anti-human IgG (red). GA733 was detected by mouse anti-human GA733 antibody as a primary antibody and Alexa-488 conjugated anti-mouse IgG (green) as a secondary antibody. The nucleus was stained with TO-PRO-3 (blue).

2.10. Immunological Analysis of Plant-Derived Recombinant Chimeric Protein. Six-week-old female BALB/c mice were purchased from Da Mool Science (Daejeon, Republic Korea) and maintained in a pathogen-free environment. All mice experiments in this study were approved by the Wonkwang University Animal Ethics Committee in accordance with the guidelines of the Korean Council on Animal Care. Eightweek-old female BALB/c mice (5 per group) were injected 3 times with 1,5 , or $10 \mu \mathrm{g}$ of plant-derived GA733 or mammalian-derived GA733 (R\&D systems) in a total volume of $100 \mu \mathrm{L}$ at 2 -week intervals. The first and second immunizations were given subcutaneously (s.c.) with complete (Difco, Detroit, MI, USA) and incomplete Freund's adjuvant (Thermo Fisher Scientific, Roskilde, Denmark), respectively; the third dose was administered intraperitoneally (i.p.) in saline. Blood samples were collected by retroorbital bleeding before the experiment and 10 days after the second immunization; 10 days after the third immunization, mice were bled individually via the retroorbital plexus and sacrificed. $100 \mu \mathrm{L} /$ well of sera $(1 \mu \mathrm{g} / \mathrm{mL}$ in PBS $)$ were applied to ELISA plates coated with human colorectal cells from lines SW480, SW1116, and SW620, and with human breast cancer cells from line MCF-7 $\left(4 \times 10^{4}\right.$ cells/well $)$ and incubated for $2 \mathrm{~h}$ at RT. $100 \mu \mathrm{L} /$ well secondary antibody HRP-conjugated goat anti-mouse IgG (Animal genetics) diluted in PBS $(1: 8,000)$ were applied and incubated for $2 \mathrm{~h}$ at RT. The signals were detected using soluble TMB (3.3', $5.5^{\prime}$-tetramethylbenzidine) substrate (KPL, Gaithersburg, MD, USA). The results were read by Sunrise (TECAN) at $450 \mathrm{~nm}$ and presented as mean $\pm \mathrm{SD}$.

\section{Results}

3.1. Generation of Transgenic Plants Expressing GA733K, GA733-FcK, and GA733-Fc. PCR analysis of the genomic DNA was performed to confirm the presence of transgene 
in 10 randomly selected transgenic lines from each type of vectors among the regenerated plants (Figure 2). The transgenic plants lines with GA733K, GA733-FcK, and GA733-Fc had the expected amplified bands at 780, 1473, and $1461 \mathrm{bp}$, respectively. Semi-quantitative RT-PCR analysis was carried out to confirm mRNA expression in randomly selected transgenic plants using specific primers (Figure 3 ). All tested GA733K transgenic plants had the band at $384 \mathrm{bp}$, while the GA733-FcK and GA733-Fc transgenic plants had a band at $534 \mathrm{bp}$. The actin band was detected at $214 \mathrm{bp}$. The ratios of target gene to actin differed slightly among the transgenic lines, which suggested that different transgenic plants had different expression levels of transgene RNA.

3.2. Effect of the KDEL Sequence on the Expression of GA733Fc. Protein extracts from GA733-FcK and GA733-Fc transgenic plants were analyzed by western blotting (Figure 4). In order to confirm the effect of the KDEL sequence on GA733Fc expression, leaf tissues were homogenized in $1 \times$ PBS buffer with or without protease inhibitor (Roche Diagnostics). Transgenic lines with GA733-FcK (T303 and T305) showed an approximately $65 \mathrm{kDa}$ protein band, similar to the positive control; however, this $65 \mathrm{kDa}$ band was not detected by either the anti-human Fcy antibody (Figure 4, anti-Fc) or the anti-human GA733 antibody with protease inhibitor in the transgenic lines with GA733-Fc (T103 and T108) (Figure 4, anti-GA733). In the T303 and T305 protein samples treated with protease inhibitor (PI), an approximately $140 \mathrm{kDa}$ protein band was detected by the anti-Fc antibody, while in the T303 protein sample without PI, the $140 \mathrm{kDa}$ protein band was not detected (Figure 4, anti-Fc). In T303 without PI, the protein bands were generally weaker than in T303 with PI. In both the T303 and T305 samples with PI, the 65 and $140 \mathrm{kDa}$ protein bands were detected with the GA733specific antibody; however, no protein bands were observed in T103 and T108 (Figure 4, anti-GA733). No band was observed in the non-transgenic plants (data not shown).

3.3. Effect of the Fc Fragment on GA733 Expression. To confirm the expression of the GA733 and GA733-Fc fused to KDEL, western blot analysis was conducted (Figure 5). In all the transgenic lines with GA733-FcK (T303, T305, and T312), an approximately $65 \mathrm{kDa}$ band was detected by the anti-Fc antibody, whereas in the transgenic lines with GA733K (T202, T203, and T207) no protein band was detected (Figure 5, Anti-Fc). However, in some of both the GA733K and GA733-FcK transgenic lines, the $35 \mathrm{kDa}$ protein band was detected with the anti-GA733 antibody (Figure 5, anti-GA733). Among all the tested GA733K transgenic lines treated with or without protease inhibitor, T207 seemed to have the highest expression. Among all the tested GA733FcK transgenic lines, T303 had the highest expression (Figure 5). In general, the density of the GA733 protein bands recognized with the anti-GA733 antibody in GA733K transgenic plants was slightly stronger than that of the GA733-FcK transgenic plants, indicating that the Fc did not seem to enhance the GA733 expression level (Figure 5).

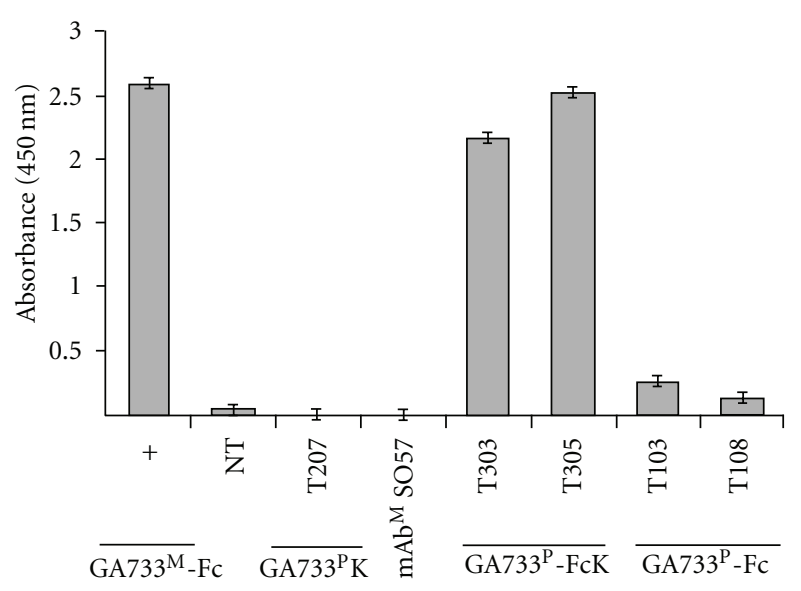

FIGURE 7: Sandwich ELISA of recombinant proteins. ELISA was conducted by using 96-well plate coated with mouse anti-human GA733 antibody. +: positive control, mammalian-derived GA733Fc antibody; NT: negative control, non-transgenic plant; $\mathrm{mAb}$ SO57: human antirabies monoclonal antibody.

3.4. Confocal Immunofluorescence for Confirmation of GA733K, GA733-FcK, and GA733-Fc Expression in Plant Cells. Expression of the cancer vaccine candidates GA733K, GA733-FcK, and GA733-Fc in transgenic plants was investigated by immunofluorescence staining (Figure 6). In the analysis, GA733, Fc, and the nucleus were stained in green, red, and blue, respectively. Green fluorescence activity was observed in leaf samples from GA733K and GA733-FcK transgenic plants but not in GA733-Fc plants (Figure 6, antiGA733). No red signal was detected in GA733K transgenic plants. Red fluorescence was detected in leaf samples from GA733-FcK plants but rarely observed in GA733-Fc plants (Figure 6, anti-Fc). No green or red signal was detected in non-transgenic plants.

3.5. ELISA for Confirmation of Recombinant GA733-Fc Expression. ELISA was conducted to confirm expression of recombinant GA733-Fc. A 96-well plate was coated with mouse anti-human GA733 antibody, and soluble plant leaf protein extracts were applied. Leaf extracts from 2 GA733FcK transgenic lines (T303 and T305), 2 GA733-Fc transgenic lines (T103 and T108), and a GA733K transgenic line (T207) were analyzed by ELISA. HRP-conjugated antihuman IgG Fc $\gamma$ was used as a secondary antibody to confirm GA733-Fc expression. Both the T303 and T305 transgenic lines (GA733-FcK) showed significantly greater absorbance than T103 and T108 (GA733-Fc) (Figure 7). No absorbance was detected in the transgenic line with GA733K (T207), which does not have the $\mathrm{Fc}$ fragment or with $\mathrm{mAb} \mathrm{b}^{\mathrm{M}} \mathrm{SO} 57$ (antirabies antibody), which lacks the GA733 fragment. NT tobacco served as a negative control. A recombinant human EpCAM/TROP-1 Fc chimera (R\&D systems), which is the positive control, showed high absorbance.

3.6. N-Glycosylation Analysis. The GA733-FcK protein was purified from transgenic plants using a protein A affinity column for glycan structure analysis. However, the GA733-Fc 


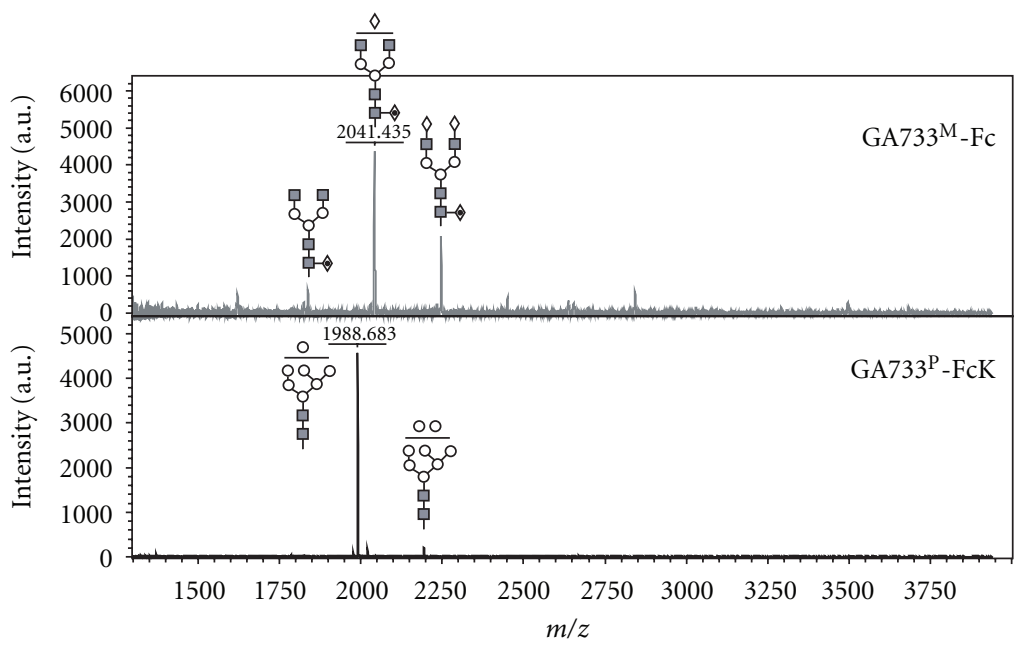

FIGURE 8: Glycosylation analysis of GA733 ${ }^{\mathrm{M}}-\mathrm{Fc}$ and GA733 ${ }^{\mathrm{P}}$-FcK recombinant proteins. The profiles of $N$-glycans released from $\mathrm{GA} 733^{\mathrm{M}}$-Fc and $G A 733^{\mathrm{P}}-\mathrm{FcK}$ were analyzed using MALDI-TOF mass spectrometry after permethylation. The proposed glycan structures for each peak were designated. GlcNAc, mannose, galactose, and fucose are depicted with black square, white circle, white diamond, and diamond with a dot inside, respectively.

protein could not be purified from GA733-Fc transgenic plants since its expression was very low. $\mathrm{GA} 733^{\mathrm{M}}-\mathrm{Fc}$ had mostly glycan structures with mammalian-specific $\alpha(1,6)$ fucose residues, whereas $\mathrm{GA} 733^{\mathrm{P}}-\mathrm{FcK}$ had oligomannose glycan structures (Figure 8).

3.7. Immune Response of Mice Injected with Purified GA733P FcK and $G A 733^{M}-F c$. A GA733-specific serum IgG antibody immune response was induced in all mice injected with purified GA733 ${ }^{\mathrm{P}}$-FcK or GA733 ${ }^{\mathrm{M}}$-Fc (Figure 9). The serum of the injected mice contained IgGs recognizing the human colorectal cancer cell lines SW480, SW1116, and SW620, as well as the human breast cancer cell line MCF-7. With all 3 human colorectal cancer cell lines (SW480, SW1116, and SW620), serum from mice injected with $\mathrm{GA} 733^{\mathrm{P}}-\mathrm{FcK}$ showed comparable absorbance to serum from mice injected with GA733 ${ }^{\mathrm{M}}-\mathrm{Fc}$ (Figure 9). With all the colorectal cell lines, the absorbance rapidly decreased in the serum from mice injected with $\mathrm{GA} 733^{\mathrm{M}}$-Fc, whereas the absorbance level slowly decreased in the serum from mice injected with GA733 ${ }^{\mathrm{P}}-\mathrm{FcK}$ at dilution factor of $1: 50$ and $1: 100$. Mice injected with $1 \times$ PBS did not show any immune response. Even with the human breast cancer cell line MCF-7, serum from mice injected with $\mathrm{GA} 733^{\mathrm{P}}-\mathrm{FcK}$ showed comparable absorbance to serum from mice injected with $\mathrm{GA} 733^{\mathrm{M}}$-Fc.

\section{Discussion}

Here, we describe the successful expression of chimeric GA733-Fc, which is a fusion of GA733 to a human IgG Fc fragment, in plants. In this study, 3 different transgenic plant lines expressing GA733K, GA733-FcK, or GA733-Fc were established in order to investigate the effect of the Fc fragment and the KDEL retention signal on GA733 expression and bioactivities. Both PCR and RT-PCR analyses showed that all randomly tested transgenic plants with each of the transgenes (GA733K, GA733-FcK, and GA733-Fc) expressed the transgene transcript. The immunoblot analysis showed some variation in protein expression. GA733-FcK transgenic plants had stronger protein expression than GA733-Fc transgenic plants, which did not have any detectable protein expression. These results indicate that the ER retention signal KDEL stabilized and enhanced GA733-Fc expression. This higher expression of GA733-FcK can be explained by its localization in ER [21] and consequently is protected from proteolytic activity found through the secretary pathway, in intracellular and extracellular spaces [21, 22]. However, no significant differences in protein expression were observed between GA733K and GA733-FcK. Therefore, it seems that the $\mathrm{Fc}$ fragment does not increase GA733 protein expression. In order to confirm the stability of the GA733-Fc fusion protein, western blot analysis was performed, and it was shown that the protein samples homogenized with or without proteinase inhibitor had similar expression levels, which indicated that the $\mathrm{Fc}$ fusion proteins are stable.

Confocal immunofluorescence analysis reconfirmed that the expression of GA733K and GA733-FcK in plants was higher than the GA733-Fc expression in plants. In addition, GA733-FcK transgenic plants expressed GA733 fused to the human Fc fragment. In the ELISA analysis, the GA733FcK transgenic plants (T303 and T305) showed higher absorbance than the GA733-Fc transgenic plants (T103 and T108), indicating that the KDEL sequence enhanced GA733Fc expression. The absorbance signal observed in the GA733FcK and GA733-Fc transgenic plants was not detected using the anti-Fc antibody in the GA733K transgenic plants or using $\mathrm{mAb} \mathrm{M}^{\mathrm{M}} \mathrm{SO} 57$, indicating that GA733 is fused to the $\mathrm{Fc}$ fragment and is expressed in GA733-FcK transgenic plants. The higher yield of GA733-Fc in lines T305 and T303 and of GA733 with KDEL in lines T202, T203, and T207 might reflect the use of the endoplasmic reticulum 


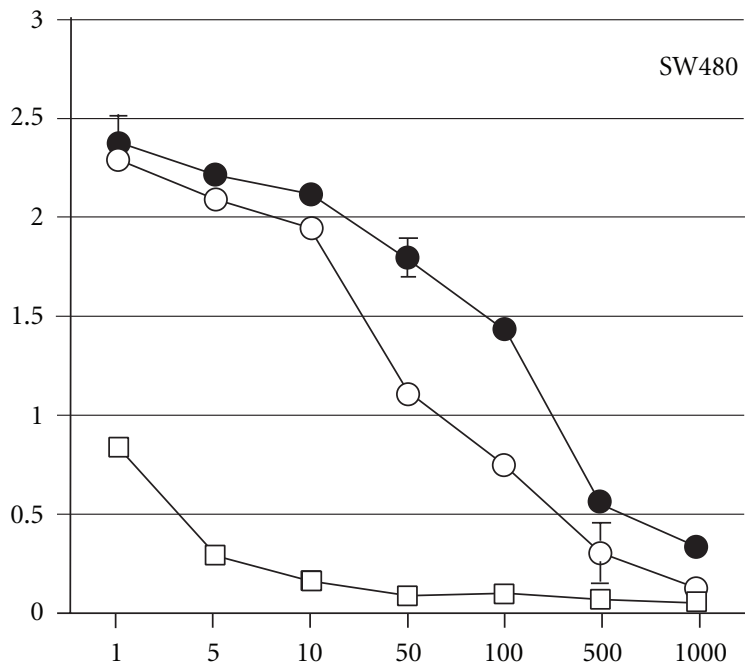

(a)

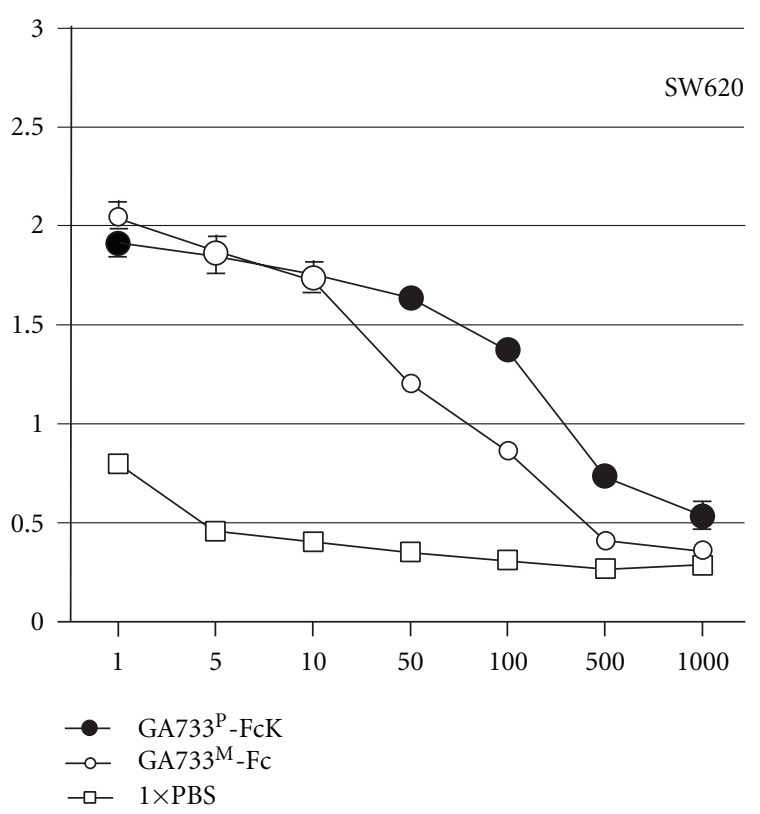

(c)

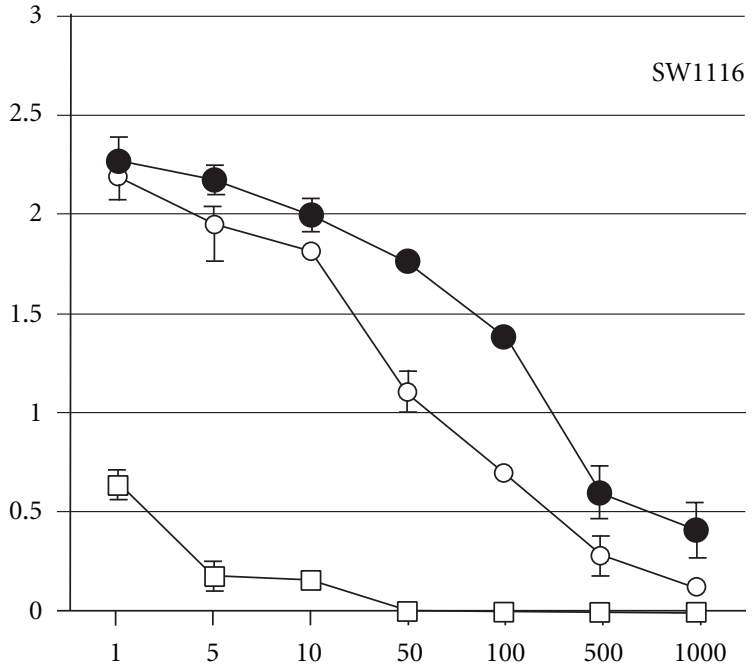

(b)

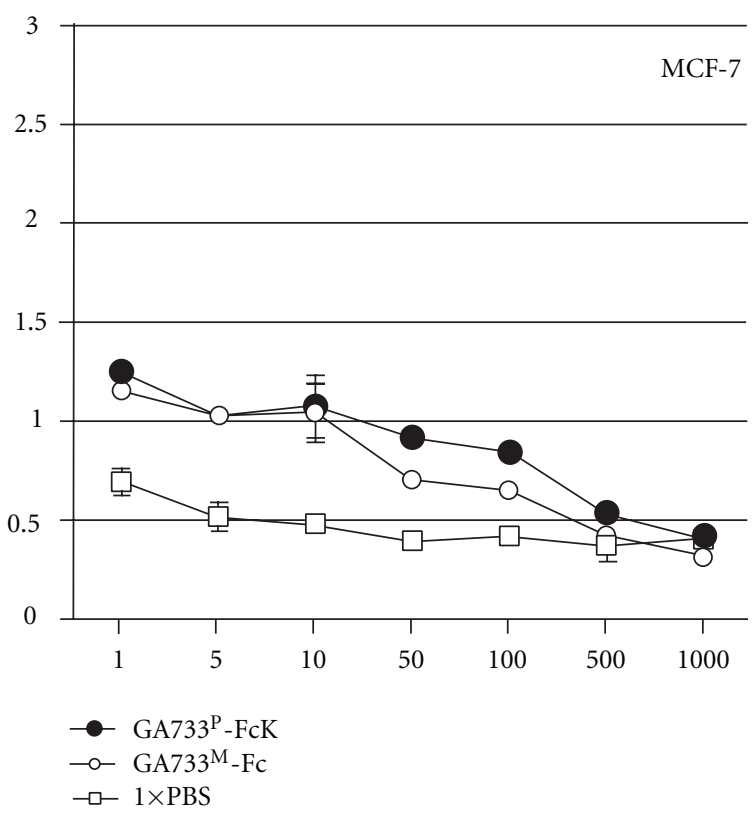

(d)

FIGURE 9: Immune response of mice injected with plant-derived GA733-FcK (GA733 ${ }^{\mathrm{P}}$-FcK) and mammalian-derived GA733-Fc (GA733 Fc, the recombinant human EpCAM/TROP-1 Fc chimera). SW480, SW1116, and SW620 are human colorectal cancer cell lines; MCF-7 is human breast cancer cell line. $X$-axis, serum dilution (1/100X); $Y$-axis, OD $450 \mathrm{~nm}$.

retrieval motif KDEL (Lys-Asp-Glu-Leu), which was fused to the C-terminus of the $\mathrm{Fc}$ fragment and/or GA733 in order to retain the recombinant protein in the endoplasmic reticulum [11]. We observed lower expression of GA733Fc when the KDEL sequence is absent in lines T103, T108, and T110, which indicates that the endoplasmic reticulum is a good subcellular location for the accumulation of recombinant protein. Therefore, in this study, the GA733Fc fusion protein did not provide better yield and stability than GA733 without the Fc fragment fusion. Nevertheless, the reason that GA733 was fused to the Fc fragment was the obvious advantage of an easy one-step purification procedure using the protein A method $[17,23]$. As a source of recombinant GA733-Fc antigen, soluble Fc fusion proteins have become valuable reagents for immunotherapy and laboratory investigations. Furthermore, the immunoadhesin antibody-like protein design resulted in soluble protein accumulation in plant tissues.

GA733-Fc could not be purified from transgenic plants since the expression was very low. However, the soluble GA733-FcK protein was successfully purified using a proteinA affinity column for glycan structure analysis and in vivo animal immunizations. In the glycosylation analysis, GA733 ${ }^{\mathrm{M}}$-Fc had mostly glycan structures with mammalianspecific $\alpha(1,6)$-fucose residues, whereas GA733 $3^{\mathrm{P}}$-FcK had high-mannose glycan structures. These results indicate that 
the KDEL ER retention signal efficiently retained the glycoproteins, yielding proteins with high mannose [11].

In $\mathrm{BALB} / \mathrm{c}$ mice, the immune response to $\mathrm{GA} 733^{\mathrm{P}}$ FcK appeared to be slightly stronger than that of an equal dose of $\mathrm{GA} 733^{\mathrm{M}}-\mathrm{Fc}$. It seems likely that this differential immunoreactivity is due to the different glycosylation patterns in $\mathrm{GA} 733^{\mathrm{P}}-\mathrm{FcK}$ and $\mathrm{GA} 733^{\mathrm{M}}-\mathrm{Fc}$. The reactivity of antiGA733 ${ }^{\mathrm{P}}$-FcK sera with all 3 tested human colorectal cancer cell lines (SW480, SW1116, and SW620) appeared to be slightly higher than that of GA733 ${ }^{\mathrm{M}}-\mathrm{Fc}$ sera at sera dilutions of $1: 50$ and $1: 100$ (Figure 9). The reactivity of both antiGA733 ${ }^{\mathrm{P}}-\mathrm{FcK}$ and anti-GA733 ${ }^{\mathrm{M}}-\mathrm{Fc}$ sera was much weaker with the human breast cancer cell line MCF-7 than with the human colorectal cancer cell lines (Figure 9). However, a similar trend in differential immunoreactivity between GA733 ${ }^{\mathrm{P}}$-FcK and $\mathrm{GA} 733^{\mathrm{M}}-\mathrm{Fc}$ was also observed at sera dilutions of $1: 50$ and $1: 100$ with the human breast cancer cell line MCF-7. These results indicate that $\mathrm{GA} 733^{\mathrm{P}}-\mathrm{FcK}$ with high mannose has immunogenicity comparable to GA733 ${ }^{\mathrm{M}}$ Fc. The antigen-antibody complex can enhance the efficiency and effectiveness of vaccination by targeting the vaccine to APCs. It has not been reported that the common Fcreceptors on mouse APC do interact efficiently with human $\mathrm{IgG}_{1} \mathrm{Fc}$ However, in our unpublished data, the human $\mathrm{Fc}$ of a full size human monoclonal antibody has interaction with the mouse Fc receptor (CD64). Thus, it is speculated that the human Fc fragment should be specific for CD64 located on the surface of dendritic cells, which is a known entry portal to the antigen-processing pathway in mice. The Fc fragment is specific for CD64 located on the surface of dendritic cells, which is a known entry portal to the antigenprocessing pathway. In model systems, the antigen delivered by antibody has been shown to be processed and presented by dendritic cells at least 100- to 1000-fold more efficiently than nontargeted antigen [14]. In addition, the oligomannosetype $N$-glycan structure would be expected to cause an enhanced immune response through the mannose receptor (MR) on macrophages and dendritic cells recognizing the oligomannose of GA733-FcK [24]. According to a previous study [11], the ER-type glycans on glycoprotein which are also known as oligomannose glycan-type can render the glycoprotein more immunogenic, producing IgG against the oligomannose glycosylated protein itself.

\section{Conclusion}

In this study, the data clearly demonstrate expression of the colorectal cancer vaccine candidate GA733 and the antigen-antibody complex protein GA733-Fc in tobacco plant expression systems. Fusion of the $\mathrm{Fc}$ fragment of human IgG to the C-terminus of GA733 and the ER retention KDEL in GA733-FcK generating oligomannose glycosylated proteins is an ideal strategy to easily purify recombinant GA733 vaccine candidate proteins and to enhance accumulation of the recombinant proteins with oligomannose for comparable immunogenicity to the non-KDEL-tagged mammalian-derived proteins in a plant expression system.

\section{Acknowledgments}

This paper was supported by grants from Korea Institute of Planning and Evaluation for Technology of Food, Agriculture, Forestry and Fisheries (iPET-Code no. 111096-031-SB010), the Korean Rural Development Administration (Code no. PJ007492), National Research Foundation of Korea Grant funded by the Korean Government (MEST) (NRF-2011-0026969). There were no specific author's contribution nor conflict of interests in this paper.

\section{References}

[1] M. Neighbors, D. Apt, J. C. C. Chang et al., "EpCAM-specific vaccine response by modified antigen and chimeric costimulatory molecule in cynomolgus monkeys," Journal of Immunotherapy, vol. 31, no. 7, pp. 644-655, 2008.

[2] V. Andrianov, R. Brodzik, S. Spitsin et al., "Production of recombinant anthrax toxin receptor (ATR/CMG2) fused with human Fc in planta," Protein Expression and Purification, vol. 70, no. 2, pp. 158-162, 2010.

[3] A. Armstrong and S. L. Eck, "EpCAM: a new therapeutic target for an old cancer antigen," Cancer Biology and Therapy, vol. 2, no. 4, pp. 320-325, 2003.

[4] W. Du, H. Ji, S. Cao et al., "EpCAM: a potential antimetastatic target for gastric cancer," Digestive Diseases and Sciences, vol. 55, no. 8, pp. 2165-2171, 2010.

[5] M. Munz, P. A. Baeuerle, and O. Gires, "The emerging role of EpCAM in cancer and stem cell signaling," Cancer Research, vol. 69, no. 14, pp. 5627-5629, 2009.

[6] T. Verch, D. C. Hooper, A. Kiyatkin, Z. Steplewski, and H. Koprowski, "Immunization with a plant-produced colorectal cancer antigen," Cancer Immunology, Immunotherapy, vol. 53, no. 2, pp. 92-99, 2004.

[7] V. Yusibov and S. Rabindran, "Recent progress in the development of plant-derived vaccines," Expert Review of Vaccines, vol. 7, no. 8, pp. 1173-1183, 2008.

[8] A. Góra-Sochacka, P. Redkiewicz, B. Napiórkowska, and A. Sirko, "Plant-based production of recombinant cytokines," Postepy Biochemii, vol. 55, no. 1, pp. 85-94, 2009.

[9] R. Brodzik, S. Spitsin, M. Golovkin et al., "Plant-derived EpCAM antigen induces protective anti-cancer response," Cancer Immunology, Immunotherapy, vol. 57, no. 3, pp. 317323, 2008.

[10] K. Ko, M. H. Ahn, M. Song et al., "Glyco-engineering of biotherapeutic proteins in plants," Molecules and Cells, vol. 25, no. 4, pp. 494-503, 2008.

[11] K. Ko, Y. Tekoah, P. M. Rudd et al., "Function and glycosylation of plant-derived antiviral monoclonal antibody," Proceedings of the National Academy of Sciences of the United States of America, vol. 100, no. 13, pp. 8013-8018, 2003.

[12] K. Ko and H. Koprowski, "Plant biopharming of monoclonal antibodies," Virus Research, vol. 111, no. 1, pp. 93-100, 2005.

[13] S. Munro and H. R. B. Pelham, "A C-terminal signal prevents secretion of luminal ER proteins," Cell, vol. 48, no. 5, pp. 899907, 1987.

[14] S. Amigorena and C. Bonnerot, "Fc receptors for IgG and antigen presentation on MHC class I and class II molecules," Seminars in Immunology, vol. 11, no. 6, pp. 385-390, 1999.

[15] R. Brodzik, M. Glogowska, K. Bandurska et al., "Plant-derived anti-Lewis Y mAb exhibits biological activities for efficient 
immunotherapy against human cancer cells," Proceedings of the National Academy of Sciences of the United States of America, vol. 103, no. 23, pp. 8804-8809, 2006.

[16] K. M. Lo, Y. Sudo, J. Chen et al., "High level expression and secretion of Fc-X fusion proteins in mammalian cells," Protein Engineering, vol. 11, no. 6, pp. 495-500, 1998.

[17] A. Ashkenazi and S. M. Chamow, "Immunoadhesins as research tools and therapeutic agents," Current Opinion in Immunology, vol. 9, no. 2, pp. 195-200, 1997.

[18] K. Ko, X. Wei, P. A. Crooks, and H. Koprowski, "Elimination'of alkaloids from plant-derived human monoclonal antibody," Journal of Immunological Methods, vol. 286, no. 1-2, pp. 7985, 2004.

[19] K. J. Lee, J. H. Jung, J. M. Lee et al., "High-throughput quantitative analysis of plant N-glycan using a DNA sequencer," Biochemical and Biophysical Research Communications, vol. 380, no. 2, pp. 223-229, 2009.

[20] J. A. Goetz, M. V. Novotny, and Y. Mechref, "Enzymatic/chemical release of O-glycans allowing MS analysis at high sensitivity," Analytical Chemistry, vol. 81, no. 23, pp. 9546-9552, 2009.

[21] A. Schouten, J. Rossien, F. A. Van Engelen et al., "The C-terminal KDEL sequence increases the expression level of a singlechain antibody designed to be targeted to both the cytosol and the secretory pathway in transgenic tobacco," Plant Molecular Biology, vol. 30, no. 4, pp. 781-793, 1996.

[22] C. I. Wandelt, M. R. I. Khan, S. Craig, H. E. Schroeder, D. Spencer, and T. J. V. Higgins, "Vicilin with carboxy-terminal KDEL is retained in the endoplasmic reticulum and accumulates to high levels in the leaves of transgenic plants," The Plant Journal, vol. 2, no. 2, pp. 181-192, 1992.

[23] M. L. Flanagan, R. S. Arias, P. Hu, L. A. Khawli, and A. L. Epstein, "Soluble Fc fusion proteins for biomedical research," Methods in Molecular Biology, vol. 378, pp. 33-52, 2007.

[24] V. Apostolopoulos, "Role of the mannose receptor in the immune response," Current Molecular Medicine, vol. 1, no. 4, pp. 469-474, 2001. 


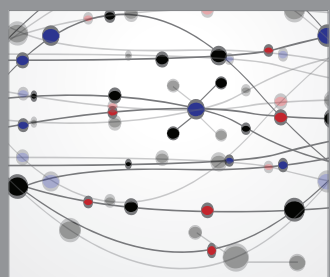

The Scientific World Journal
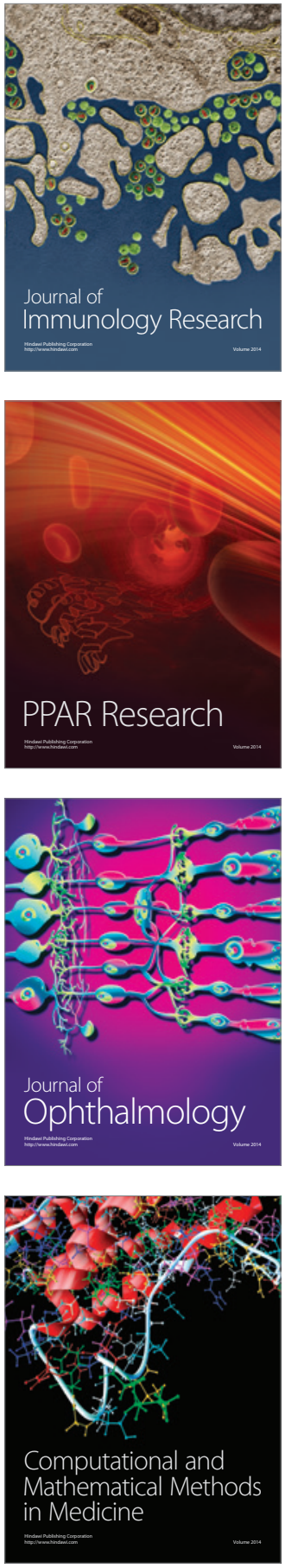

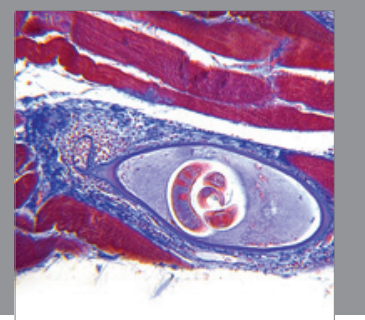

Gastroenterology

Research and Practice
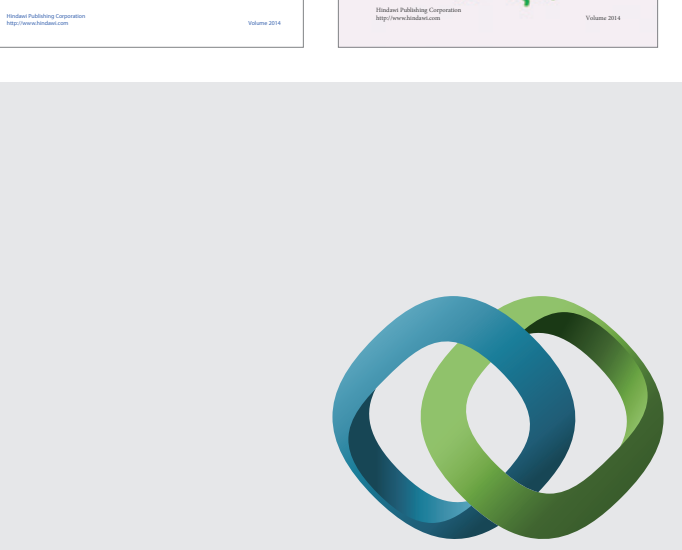

\section{Hindawi}

Submit your manuscripts at

http://www.hindawi.com
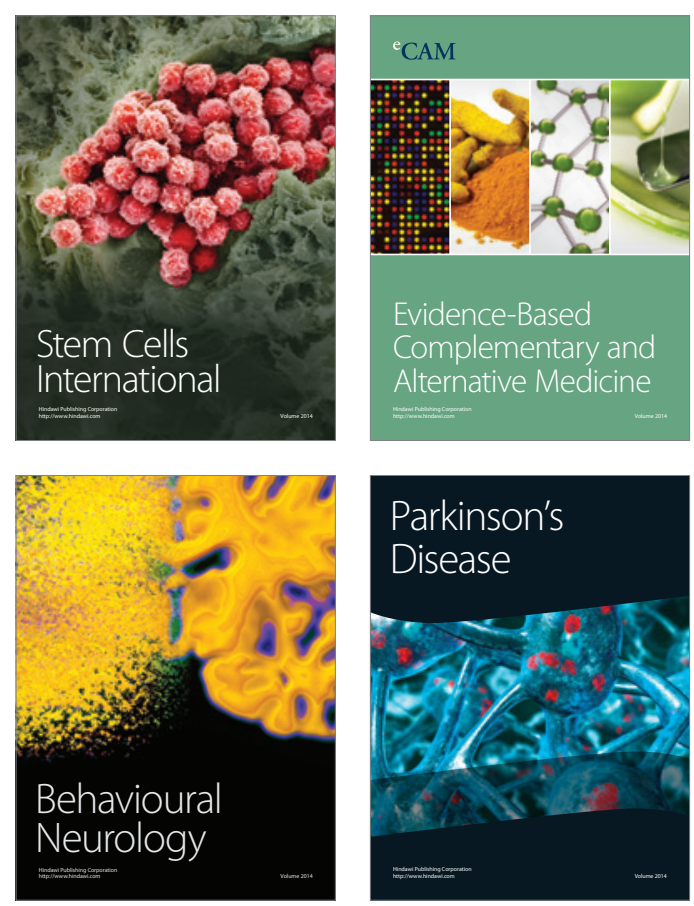

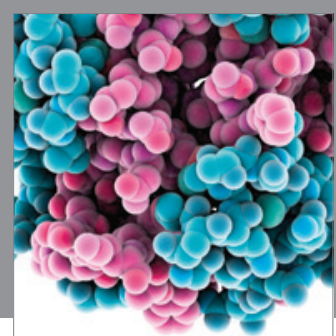

Journal of
Diabetes Research

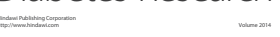

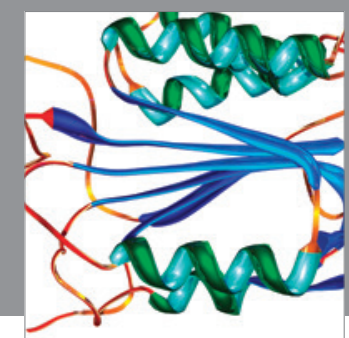

Disease Markers
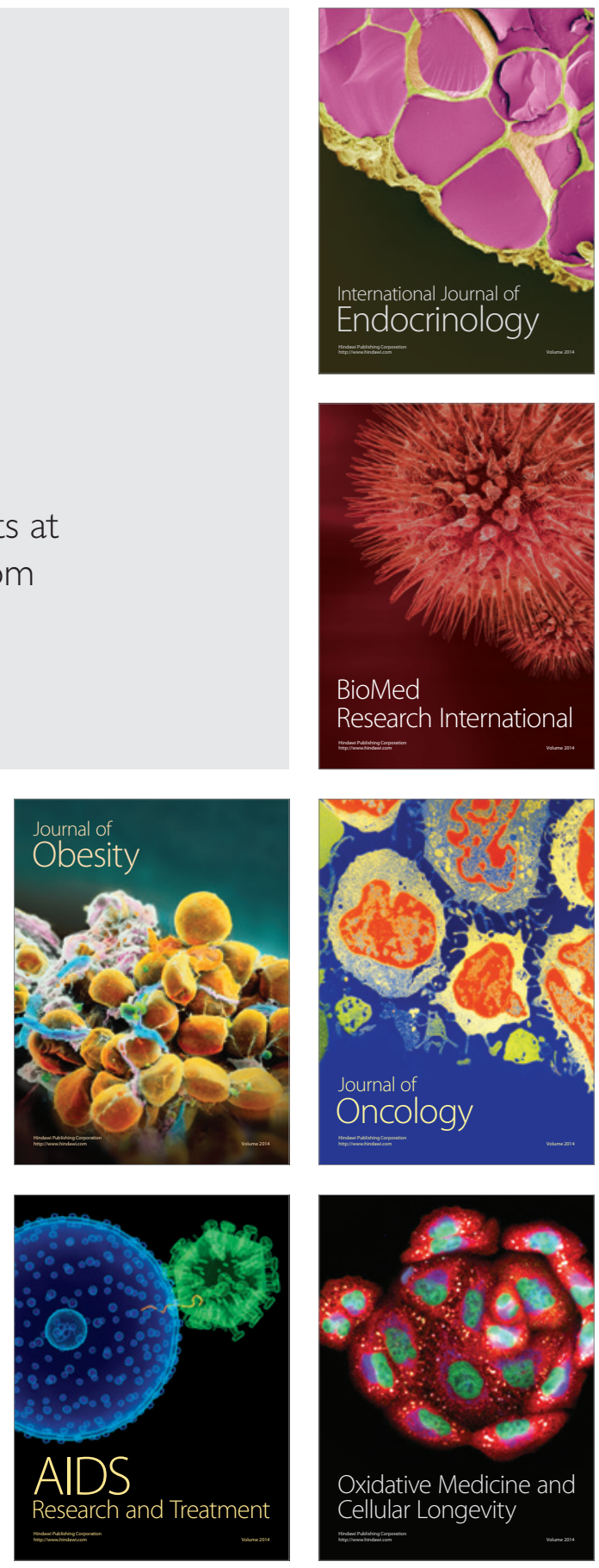